\title{
LEGISLAÇÃO AFRO-BRASILEIRA E O LUGAR QUE AS RELIGIÕES DE MATRIZ AFRICANA OCUPAM NO ENSINO DE HISTÓRIA DA ÁFRICA EM ESCOLAS DE PERNAMBUCO
}

\author{
AFRO-BRAZILIAN LEGISLATION AND THE PLACE THAT THE RELIGIONS OF AFRICAN
} ORIGIN OCCUPY IN AFRICAN HISTORY TEACHING IN SCHOOLS PERNAMBUCO

\author{
LA LEGISLACIÓN AFRO-BRASILEÑA Y EL LUGAR QUE LAS RELIGIONES DE \\ MATRIZ AFRICANA OCUPAN EN ÁFRICA ENSEÑANZA DE LA HISTORIA \\ EN LAS ESCUELAS PERNAMBUCO
}

\author{
Aurenéa Maria de Oliveira ${ }^{i}$ \\ Maria da Conceição dos Reis ${ }^{i i}$ \\ Vilde Gomes de Menezes iii \\ Cristiano Cavalcante Ferreira ${ }^{i v}$
}

\section{RESUMO}

Este artigo discute os resultados de pesquisa PIBIC (2013/2014) financiada pela FACEPE/CNPq, que teve como fim examinar, mediante a implantação da Lei 10.639/2003 em escolas estaduais e municipais das cidades de Recife e Olinda, em Pernambuco, e a partir do trato ou não das religiões afro-brasileiras no ensino de História da África, o lugar que o negro e sua cultura, especificamente religiosa, ocupam nos espaços pesquisados. Para tal fez-se uso da Teoria do Discurso elaborada por Ernesto Laclau e da metodologia da Análise do Discurso francesa objetivando: primeiro, identificar os discursos hegemônicos que dão conta do lugar do negro e de sua cultura no ensino tratado; segundo, entender, através das relações de sentido, as ideologias que perpassam as falas dos entrevistados e que justificam o lugar desse negro e de sua cultura religiosa. Neste aspecto, os resultados apontam para "certa" visibilidade cultural desses povos, mas com invisibilidade, no entanto, de suas tradições religiosas..

PALAVRAS-ChAVE: Legislação Afro-Brasileira. Lei no 10.639/2003. Ensino de história da África

\begin{abstract}
This paper discusses the results of PIBIC (2013/2014) research financed by FACEPE/CNPq, whose purpose was to examine, through the implementation of Law 10.639/2003 in state and municipal schools of the cities of Recife and Olinda, in Pernambuco, and from the Or not Afro-Brazilian religions in teaching History of Africa, the place that the black and its culture, specifically religious, occupy in the spaces surveyed. To this end, the Discourse Theory elaborated by Ernesto Laclau and the French Discourse Analysis methodology were used: first, to identify the hegemonic discourses that give an account of the place of the Negro and his culture in the treated teaching; Second, to understand, through the relations of meaning, the ideologies that permeate the speeches of those interviewed and that justify the place of this black man and his religious culture. In this respect, the results point to a cultural visibility of these peoples, but, invisibly however, from their religious traditions.
\end{abstract}

KEYWORDS: Afro-Brazilian legislation. Law 10.639/2003. African history teaching. 


\section{RESUMEN}

En este artículo se analiza el resultado de la búsqueda PIBIC (2013/2014), financiado por FACEPE/ CNPq, que tenía como objetivo examinar, a través de la aplicación de la Ley 10.639/2003 en las escuelas estatales y municipales en las ciudades de Recife y Olinda, y desde el tracto o no las religiones afro-brasileña en la Historia de África, el lugar del negro y su cultura, específicamente religioso, ocupar los espacios estudiados. Discurso.

PALABRAS CLAVE: La legislación afro-brasileña. Ley 10.639/2003. Enseñanza de la historia de África.

\section{INTRODUÇÃ̃O}

Para Rosemberg, Brazilli e Silva (2003) o racismo é uma ideologia em que grupos, com base em características biológicas e culturais verdadeiras ou atribuídas, são percebidos como uma raça etnicamente diferente e inferior. As autoras completam que essa inferioridade é atribuída à população afro-brasileira devido a seus fenótipos negróides, sua história, sua religiosidade e sua cultura.

Além dessa inferioridade, as pessoas negras também experimentam a discriminação racial, conceituada pelo Estatuto da Igualdade Racial como:

[...] toda distinção, exclusão, restrição ou preferência baseada na raça, cor, descendência ou origem nacional ou étnica que tenha por objeto anular ou restringir o reconhecimento, gozo ou exercício, em igualdade de condições, de direitos humanos e liberdades fundamentais nos campos político, econômico, social, cultural, ou em qualquer outro campo da vida pública ou privada (BRASIL, 2010, p. 03).

Foi essa discriminação que levou os movimentos sociais negros a reivindicar a educação escolar para atender à população afro-brasileira, proporcionando a ela uma possível ascensão com superação de suas condições. Esta luta pela inclusão no processo de escolarização oficial não é recente, mas é historicamente desconsiderada pelas políticas locais e nacionais (REIS; SOUZA; MENEZES, 2014).

Neste aspecto, políticas públicas educacionais ao serem implementadas numa dimensão democrática, devem contribuir com a garantia de direitos, legislações e práticas que tenham como propósito a universalização do acesso e da permanência na escola com equidade e qualidade, possibilitando o favorecimento da democracia, da igualdade e da solidariedade entre as pessoas nacionais (REIS; SOUZA; MENEZES, 2014).

Porém, há um desrespeito acerca das políticas educacionais brasileiras junto à população afro-brasileira haja vista que historicamente a ela foi e ainda é negada a garantia de uma educação de qualidade, com respeito às diferenças, divulgação e valorização de sua cultura e

n.1 1 p.122-138

jan./abr. 2017 eISSN 2178-8359


afirmação de sua identidade. Contudo, no decorrer do tempo, pequenas mudanças educacionais ocorrem a partir de mobilizações feitas sobre seu direito à educação, pela superação do racismo, pelo autoconhecimento e auto-afirmação do povo negro e por sua ascensão econômica e social.

Sendo assim, as primeiras mudanças que acontecem na área da educação escolar no Brasil se estabelecem ainda na sociedade burguesa do período imperial, impulsionadas pelas transformações econômicas e políticas que favoreceram ao desenvolvimento social do país. Neste cenário, a educação escolar passa a ser reivindicada democraticamente para todos como um meio de ascensão na sociedade brasileira (REIS, 2012).

Na década de 1930, os afro-brasileiros se apoderam desta ideia sobre a escola, impelidos pelo processo de modernização do Brasil. Mesmo que este processo não tenha se consolidado enquanto uma oportunidade de mobilidade social para a população da diáspora negra, ou, mesmo que a educação não tivesse o mínimo de qualidade que pudesse favorecer inserções, a escola era vista pelos afro-brasileiros enquanto um espaço de oportunidades para também se "ser gente" (REIS, 2012).

Neste caso, a história da educação no Brasil revela que a ausência de uma educação escolar voltada para as relações étnico-raciais justifica a legislação específica que criou a Lei $\mathrm{n}^{\circ}$ 10.639/2003 que torna obrigatório o ensino da História e Cultura Afro-brasileira e Africana nos estabelecimentos de ensino fundamental e médio, oficiais e particulares de todo o território nacional.

Diante disso, este artigo discute a presença e atuação de uma legislação que trate das relações étnico-raciais no país através da exposição dos principais resultados de uma pesquisa PIBIC, realizada entre 2013 e 2014, que teve como objetivo examinar, mediante a implantação da Lei 10.639/2003 em escolas estaduais e municipais das cidades de Recife e Olinda, em Pernambuco, e a partir do trato ou não das religiões afro-brasileiras no ensino de História da África, o lugar que o negro e sua cultura, especificamente religiosa, ocupam nos espaços pesquisados.

\section{POLÍTICA E LEGISLAÇÃO AFRO-BRASILEIRA}

Ao longo da história do Brasil a legislação educacional e as demandas referentes à população afro-brasileira não foram percebidas pelas políticas educacionais do país. Há assim limites nas políticas públicas direcionadas à educação por não se considerar relevante a educação das 
relações étnico-raciais para, por exemplo, a reestruturação do currículo escolar e para a formação dos educadores para atender essa especificidade (REIS, 2012).

Este tipo de educação é aquele que revê e ressignifica as relações étnico-raciais, fortalecendo e despertando a consciência negra, entre pessoas de qualquer cor, através do orgulho de sua identidade, permitindo-lhes identificar a importância do outro em sua própria história e cultura. Considerando que estas relações "[...] impõem aprendizagens entre brancos e negros, troca de conhecimentos, quebra de desconfianças, projeto conjunto para construção de uma sociedade justa, igual, equânime" (BRASIL, 2004, p. 02), o objetivo da educação das relações étnico-raciais é:

[...] a divulgação e produção de conhecimentos, bem como de atitudes, posturas e valores que eduquem cidadãos quanto à pluralidade etnicorracial, tornando-os capazes de interagir e de negociar objetivos comuns que garantam, a todos, respeito aos direitos legais e valorização de identidade na busca da consolidação da democracia brasileira (BRASIL, 2004, p. 02).

Sobre isso a Declaração Universal dos Direitos Humanos, proclamada em 1948 pela Organização das Nações Unidas, já concebia a educação como um direito social para a humanidade, contribuindo para que ao longo do tempo a escola fosse se configurando em espaço fundamental de acesso, tornando-se um direito de todas as pessoas, em todos os países. Dessa forma, a educação escolar passava a ser determinada pelo Estado Federal que tinha a função de elaborar leis e políticas para atender sua população. Porém no Brasil é só em 1988 que é promulgada a Constituição Federal do Brasil, considerada a "Constituição Cidadã", instituindo, através do Artigo 206-I, igualdade de condições para o acesso e permanência na escola.

O movimento social negro teve participação efetiva nesta mobilização e também na discussão para elaboração da Lei no 9.394/1996 através das comemorações pelo Centenário da Abolição em 1988 e pelos 300 Anos da Morte de Zumbi dos Palmares em 1995. O Art. $3^{\circ}$ da referida lei expressa que o ensino deve ser ministrado, entre outros princípios, através de "[...] liberdade de aprender, ensinar, pesquisar e divulgar a cultura, o pensamento, a arte e o saber" (BRASIL, 1996, Art. 3, p. 03) e de "[...] respeito à liberdade e apreço à tolerância" (BRASIL, 1996, Art. $3^{\circ}$, p. 03). Contudo é o Art. 26 que dá destaque a antigas demandas instituindo que: "[...] o ensino de História do Brasil deverá levar em conta as contribuições das diferentes culturas e etnias para a formação do povo brasileiro, especialmente as de matriz indígena, africana e europeia" (BRASIL, 1996, Art. 3º p. 06). 
Para regulamentar esse artigo, da atual LDBEN, surge a Lei no 10.639/2003. A promulgação desta lei foi um grito que reverberava no movimento social negro brasileiro, rompendo o histórico silenciamento sobre a história e cultura afro-brasileira nas escolas.

A escola é um dos espaços, talvez o mais competente, no qual as representações negativas sobre a pessoa negra são disseminadas. Para Nascimento (1978) e Munanga (1996) quando os integrantes da população afro-brasileira passam a ter acesso à escola oficial começam a identificar que esta é uma das responsáveis pela perpetuação das desigualdades raciais, ao, entre outros passos, apregoar uma educação de embranquecimento cultural. Mas também, essa instituição é um espaço social de organização, construção e socialização do conhecimento e da cultura e que, portanto, carrega o potencial de ser o local onde as negatividades referentes ao outro possam ser superadas.

Nascimento (1978) afirma que a história da África, o desenvolvimento de suas culturas e civilizações e as características do seu povo nunca foram conteúdos de ensino das escolas brasileiras, pelo contrário, a educação formal de característica eurocentrista historicamente, desqualificou o Continente Africano e seus moradores, inferiorizando os afro-brasileiros.

Foram esses silenciamentos e práticas de reprodução da discriminação racial na escola que motivaram a luta por uma educação das relações étnico-raciais, destacando a preocupação com a História da África e dos africanos, as lutas dos negros no Brasil, a valorização de sua cultura, incluindo aqui a presença de suas religiões e a contribuição delas na formação da sociedade brasileira.

\section{ENSINO DE HISTÓRIA DA ÁFRICA}

A reivindicação por conteúdos de ensino que contemplem a cultura e história da população afro-brasileira e africana vem desde o $1^{\circ}$ Congresso do Negro Brasileiro, realizado em 1950 no Rio de Janeiro e promovido pelo Teatro Experimental do Negro. Tal reivindicação foi intensificada em 1978 com o ressurgimento dos movimentos sociais negros lutando pela presença deste segmento na formulação/reformulação de currículos escolares no intuito de valorizar o papel desta etnia na História do Brasil por meio da inserção de matérias como História da África e línguas africanas (HASENBALG, 1987).

Em 1986 acontece a Convenção Nacional do Negro pela Constituinte, realizada em Brasília. Santos (2005) informa uma das lutas educacionais que atuavam no documento sistematizado nesta convenção: "O processo educacional respeitará todos os aspectos da cultura brasileira. É obrigatória a inclusão nos currículos escolares de I, II e III graus, do ensino da História da África e da História do Negro no Brasil”' (SANTOS, 2005, p. 25).

\begin{tabular}{l|c|c|c|c|c|c|} 
(C) Rev. Educ. Perspec. & Viçosa, $M G$ & v.8 & n.1 & p.122-138 & jan./abr. 2017 & eISSN 2178-8359 \\
\hline
\end{tabular}


Essas são algumas das demandas históricas da população afro-brasileira e também uma importante contribuição à democratização, proporcionando mudanças positivas nas políticas públicas educacionais. Observa-se que no início da década de 1990 várias ações governamentais foram realizadas contemplando as políticas de ações afirmativas.

O dia 20 de novembro do ano de 1995 foi marcado pela Marcha Zumbi dos Palmares Contra o Racismo, Pela Cidadania e a Vida, acontecida em Brasília. Durante o evento foi entregue ao então presidente Fernando Henrique Cardoso, o Programa de Superação do Racismo e da Desigualdade Racial. Este programa exige para a área educacional, entre outros pontos, a implementação da Convenção Sobre Eliminação da Discriminação Racial no Ensino; o monitoramento dos livros didáticos, manuais escolares e programas educativos controlados pela União e o desenvolvimento de programas permanentes de treinamento de professores.

No ano seguinte é publicado o Programa Nacional de Direitos Humanos reconhecendo a existência de desigualdades raciais e do racismo no país. Também foi realizada a revisão e eliminação de vários livros didáticos que apresentavam as pessoas de cor negra de forma estereotipada.

Paralelo às lutas de âmbito nacional, o movimento social negro com representações nos estados e municípios, têm se mobilizado para a elaboração de leis que incluam a oferta de disciplinas ou conteúdos escolares do Ensino Fundamental e Médio sobre a História dos Afro-brasileiros e do Continente Africano.

De acordo com os estudos de Silva Junior (1998) esta inclusão já vem acontecendo desde 1989 na Constituição da Bahia e nas normas de ensino deste estado. As leis que estabelecem a obrigatoriedade do ensino de História e da Cultura Afro-brasileira - difundidas pelos municípios brasileiros, a exemplo de Salvador, Porto Alegre, Belém, Aracajú, São Paulo e Teresina - também se preocuparam, entre outros fatores, com a revisão dos currículos; a qualificação dos professores e a responsabilidade do Poder Executivo pela implantação da formação continuada dos docentes quanto a esta questão. Entretanto é só em 09 de janeiro de 2003 que emerge a Lei $n^{\circ} 10.639$, alterando o artigo 26 da Lei $n^{\circ}$ 9.394/1996 e estabelecendo as diretrizes e bases da educação nacional, destacando que:

Nos estabelecimentos de ensino fundamental e médio, oficiais e particulares, tornase obrigatório o ensino sobre História e Cultura Afro-brasileira e Africana. $§ 1^{\circ} \mathrm{O}$ conteúdo programático a que se refere o caput deste artigo incluirá o estudo da História da África e dos Africanos, a luta dos negros no Brasil, a cultura negra brasileira e o negro na formação da sociedade nacional, resgatando a contribuição do povo negro nas áreas social, econômica e política, pertinentes à História do Brasil (BRASIL, 2003, Art. 26-A, p. 07).

n.1 1 p.122-138


A regulamentação dessa lei veio no ano seguinte através de parecer aprovado, por unanimidade, que culminou na Resolução No 1/2004 do Conselho Nacional de Educação (CNE). Estas leis reforçam a necessidade de diretrizes que orientem a formulação de projetos empenhados na valorização da História e Cultura dos Afro-brasileiros e dos Africanos na busca por garantir o direito à equidade de condições de vida e de cidadania, da igualdade de tratamento dado às histórias e culturas da nação brasileira e de acesso às diferentes fontes da cultura nacional.

\section{ENSINO DE HISTÓRIA DA ÁFRICA EM ESCOLAS ESTADUAIS E MUNICIPAIS DE RECIFE E OLINDA}

Dentro dessa perspectiva de efetivação de políticas étnico-raciais que valorizem o lugar do negro na cultura brasileira é que passamos agora a discutir os resultados de pesquisa de iniciação científica realizada, com o apoio da Fundação de Amparo à Ciência e Tecnologia do Estado de Pernambuco (FACEPE) e do CNPq, em escolas estaduais e municipais de Recife e Olinda a respeito do trabalho com o ensino de História da África entre 2013 e 2014. A cultura e a identidade negra no Brasil, em sua afirmação contemporânea, passam pelo processo de aceitação e respeitabilidade das religiões afro-brasileiras. Tal respeitabilidade envolve questões relacionadas à interação/hibridação dessa cultura e religiosidade no contexto brasileiro, ou seja, envolve-se às misturas que desse cenário de contatos emergiram/emergem.

Atualmente estudos acerca de sobrevivências e/ou continuidades ressignificadas da África em vários países têm levado em consideração preocupações políticas e ideológicas no sentido de apresentar o passado e com ele, o lugar do negro neste passado, desde a escravidão, mas situando-o no status que este ocupa hoje, através de suas conquistas (GABRIEL; COSTA, 2010). Dentro dessa perspectiva toma-se como ponto de referência inicial, para situar as questões de sobrevivência/memória/rearticulação dos grupos afros, as práticas culturais, de forma específica a religião que dentro de seu bojo de significações permitiu transformar-se desde o início das reordenações no Novo Mundo até os dias atuais - num lugar, a princípio de estímulo da proximidade e/ou do "retorno" a uma África idílica, isto como suporte e cerne de processos de negociação, contestação e reivindicações ao redor da identidade dos africanos/afro-descendentes em nosso país.

Discutindo esse aspecto, Dantas (1988) mostra que de forma particular, de todas essas sobrevivências apresentadas, a religiosa foi elevada a uma valorização ímpar posto que: 
[...] às culminâncias de africanidade são apresentadas como modelo de resistência no qual a manutenção da tradição da África e dos valores africanos permitiria uma forma alternativa de ser, se não a nível das relações econômicas e políticas, ao menos a nível ideológico (DANTAS, 1988, p. 20).

Ainda acerca disso, Bastide (1989) informa que a autonomia ideológica dos negros inseridos na sociedade capitalista é garantida pela sua inserção religiosa em algum grupo de origem africana que detém todo um acervo cultural e um pensamento que "permite" contato com a África. Reconhece o autor que, apesar de ter sofrido modificações, as religiões africanas não deixaram de constituir um sistema coerente de representações coletivas e de gestos rituais, não sendo um tecido de superstições como querem afirmar outros; ressalta assim, que muito pelo contrário, elas “[...] subentendem uma cosmologia, uma psicologia e uma teodicéia; enfim, que o pensamento africano é um pensamento culto" (BASTIDE, 1989, p. 11).

No entanto na cultura brasileira, as religiões, especificamente as afro-brasileiras Candomblé e Umbanda, possuem uma história de perseguição, tanto religiosa, como política e social, esta ocorrendo por meio de preconceitos e estigmas que se relacionam com o lugar de submissão que o povo negro ocupou e infelizmente ainda ocupa na sociedade brasileira. Desse modo, desde o início do processo de escravidão que estas perseguições acontecem alimentadas, primeiro, pelo catolicismo, passando pelo poder estatal, chegando aos dias atuais pela ação intolerante de segmentos religiosos advindos sobretudo de vertentes do pentecostalismo e neopentecostalismo brasileiro (OLIVEIRA, 2006).

Entretanto em nossa pesquisa, as religiões afro-brasileiras, especificando o Candomblé e a Umbanda, não são lidas como marginais, mas sim são concebidas como fundamentais na estruturação das sobrevivências da identidade dos africanos no Brasil. Esta perspectiva é trabalhada de modo a valorizar o processo de reafricanização no país, preocupação que foi levantada por Rodrigues (1977), depois por Bastide (1989) e tantos outros.

Neste sentido buscou-se na pesquisa de título "PLURALISMO E RELIGIÕES AFROBRASILEIRAS: uma discussão no âmbito das escolas estaduais e municipais de Recife e Olinda sobre o lugar do negro no currículo e ensino da História da África" investigar a escola como locus privilegiado de debate e discussão dessas questões, isso especialmente em época de globalização onde tanto a alteridade de modo geral, como a alteridade religiosa mais especificamente, pedem respeito à identidade afro-brasileira. Este respeito é analisado no trabalho a partir de um questionamento sobre o lugar que o negro, através de suas tradições religiosas de matriz africana, ocupa dentro da escola no ensino de História da África.

Desse modo foi que a pesquisa realizou uma incursão pelo interior das escolas da rede estadual e municipal de Recife e Olinda examinando o ensino de História da África e nele o

\begin{tabular}{l|c|c|c|c|c|c|} 
(C) Rev. Educ. Perspec. & Viçosa, $M G$ & v.8 & n.1 & p.122-138 & jan./abr. 2017 & eISSN 2178-8359 \\
\hline
\end{tabular}


lugar que o negro, a partir do trato ou não com as religiões afro-brasileiras Candomblé e Umbanda, ocupa. Neste aspecto o que se objetivou observar foram as implicações ou relações que se estabelecem acerca desse lugar e papel que o negro ocupa na sociedade e o status que sua cultura possui nas escolas pesquisadas por meio da presença ou não das religiões de matriz africana nesse tipo de ensino específico.

Teoricamente a investigação se fundamentou na Teoria do Discurso (TD) elaborada por Ernesto Laclau e Chantal Mouffe, pois esta possibilitou realizar a análise dos discursos não apenas do ponto de vista da fala, mas como uma ação que vai além, posto que nesta perspectiva o discurso não remete apenas aos domínios linguísticos, extrapola-os no sentido de que a nomeação é um ato que expressa relações sociais, ou seja, posições de sujeitos (LACLAU; MOUFFE, 1985). Desse modo, para estes autores não há uma distinção entre linguístico e extralinguístico à medida que por mais material que seja um objeto, esse para se constituir como tal necessita da nomeação e dos sentidos expressos em atos de fala e de disputas vivenciadas nas relações sociais (LACLAU; MOUFFE, 1985).

Assim é que de acordo com o próprio Laclau (1993) três foram os elementos possíveis que possibilitaram na atualidade o surgimento de uma Teoria do Discurso. Estes se relacionam primeiro, ao fato de que não há diferenciação entre sentidos denotativos e conotativos, à medida que os sentidos dados numa estrutura são objetos de disputa entre sujeitos que brigam por lugares na constituição e composição do social (OLIVEIRA, 2006). Em segundo lugar, o significado é permanentemente deslocado do significante, conduzindo tal movimento à impossibilidade de fixação de sentidos. Isto implica do ponto de vista linguístico na afirmação de que não há uma correlação estrita, rígida entre estes dois termos. Por fim, os arranjos estruturais apresentam uma indecidibilidade radical, isto é, se fundam sobre decisões tomadas a partir de situações em que mais de uma escolha era/é possível e, no entanto, se excluíram possibilidades reais, sem que a situação preservasse necessariamente o curso tomado (OLIVEIRA, 2006).

Isso é que impossibilita as estruturas de se fecharem na medida em que o que lhes dá o efeito de fechamento é um exterior que representa o que elas deixaram de fora e que pode sempre voltar sob a forma de um antagonismo ou deslocamento (posições de sujeitos em disputas). Isto implica no fato de que nenhuma estrutura de significação pode se fechar e de que ela não expressa apenas linguagem em si, mas ideologias que implicam em ações concretas de sujeitos que se sustentam em torno de filiações políticas (LACLAU, 1993).

Assim, através desta teoria entendemos o discurso de nossos entrevistados - representantes das secretarias de educação estaduais e municipais de Recife e Olinda, professores que lecionam História da África e gestores de escolas públicas destes municípios que ofertam a

\begin{tabular}{l|c|c|c|c|c|c|} 
(C) Rev. Educ. Perspec. & Viçosa, $M G$ & v.8 & n.1 & p.122-138 & jan./abr. 2017 & eISSN 2178-8359 \\
\hline
\end{tabular}


disciplina - não só como falas, mas como atos instituintes de práticas que reverberam e repercutem suas posições e filiações políticas adotadas e expressas em e nas salas de aula.

Diante disso, nosso estudo se concentrou no projeto político pedagógico ressignificado por nossos entrevistados nos espaços pesquisados e nas posições mais hegemônicas presentes em suas falas em se tratando de conteúdos programáticos trabalhados. Desta forma questionamos se as religiões afro-brasileiras são tratadas ou não no ensino de História da África.

No que se refere ao conceito de hegemonia, na TD ele é concebido como sendo a expressão dos discursos mais repetidos/reiterados, estes por sua vez representantes de ideologias circundantes que devido a aspectos contextuais, os mais variados, esboçam uma consistência/manutenção no que se refere a seu sentido, sentido este que é reforçado por um ou vários segmentos. Desse modo, foi atrás desses discursos hegemônicos que fomos buscando metodologicamente através da Análise de Discurso (AD) francesa, especificamente difundida no Brasil por Eni Pulcinelli Orlandi, as relações de sentido ${ }^{1}$ (2013), ou seja, os sentidos mais correntes utilizados no ensino da História da África nas escolas pesquisadas acerca das religiões de matriz africana Candomblé e Umbanda.

Assim, visitamos 04 escolas sendo uma municipal e uma estadual de Recife e as outras duas, uma municipal e estadual de Olinda. Realizaram-se nelas entrevistas semi-estruturadas com professores de História que trabalham com o ensino de História da África e com diretores; além disso, dialogamos com representantes das secretarias de educação de Olinda e Recife. Desse modo, foram entrevistados 04 gestores, 02 representantes das secretarias - um da rede municipal de Olinda e outro da rede estadual de Recife - e 04 professores que trabalham com o ensino de História da África, num total de 10 entrevistas. Os nomes desses atores/parceiros e das escolas visitadas foram mantidos em sigilo, pois este procedimento é importante para a preservação de suas identidades (FERREIRA; OLIVEIRA, 2014).

A Instrução Normativa $N^{\circ}$ 01/2012, documento do estado de Pernambuco que dá as diretrizes para o desenvolvimento do ensino regular e normal desde as séries iniciais do ensino fundamental, regulamenta como deve ocorrer o ensino de História da África. Neste caso, o presente documento diz que os temas da cultura afro-brasileira devem ser desenvolvidos não só através do ensino em questão, mas também em sala de aula de forma interdisciplinar, como tema transversalizado, aliado a outros assuntos (INSTRUÇÃO NORMATIVA/PE, 2012).

No Art. 17 dessa instrução coloca-se que: "O ensino de História do Brasil levará em conta as contribuições das diferentes culturas e etnias para a formação do povo brasileiro, especialmente as das matrizes indígena, africana e europeia" (INSTRUÇÃO NORMATIVA/PE, Art.17, p. 05). O parágrafo único afirma que: "A história e as culturas

\begin{tabular}{l|l|l|l|l|l|l} 
(c) Rev. Educ. Perspec. & Viçosa, $M G$ & v.8 & n.1 & p.122-138 & jan./abr. 2017 & eISSN 2178-8359 \\
\hline
\end{tabular}


indígena e afro-brasileira, presentes obrigatoriamente, nos conteúdos desenvolvidos no âmbito de todo currículo escolar e, em especial, no ensino de Arte, Literatura e História do Brasil, assim como a História da África, deverão assegurar o conhecimento e o reconhecimento desses povos para a constituição da nação" (INSTRUÇÃO NORMATIVA/PE, Art. 17, p. 05). O artigo e o parágrafo basicamente dão a mesma explicação para a inserção desse ensino na sala de aula, porém o importante neste caso é trazer para o centro da discussão povos que foram deixados à margem por serem tidos como inferiores:

No Brasil, a história da população negra foi amplamente documentada por sua condição escrava. Mais do que isso, na literatura sobre escravidão predominou uma visão que instituiu em circunscrever o negro e a negra, primeiro, na esfera econômica como mercadorias e, posteriormente, na esfera da cultura como exóticos, e na esfera política como grupo destituído de capacidade organizativa e propositiva (LEI 10.639/2003, p.09).

Desse modo, esse ensino em sala de aula é fundamental posto que permite discutir o negro objetivando reescrever sua história, colocando-a em lugar de destaque; igualmente, porque visa tratar a diversidade religiosa e cultural com respeito, estimulando a construção de um país democrático (FERREIRA; OLIVEIRA, 2014; FERREIRA; LOPES; OLIVEIRA, 2014).

Entretanto o ensino de História da África dentro da sala de aula exibe disputas por e de territórios. Assim é que discursos, ideologias e consequentemente posições políticas de sujeitos são silenciadas e outras são colocadas em evidência. Neste cenário, temáticas que envolvem as religiões afro-brasileiras são invisibilizadas. Isto foi evidenciado nesta pesquisa especialmente junto aos professores entrevistados que assumiram como discurso hegemônico que é importante trabalhar com a cultura africana, mas não com as religiões afro-brasileiras:

De fato acho de suma importância a presença deste ensino na sala de aula, mas não vejo necessidade de junto a ele trabalhar com o tema das religiões afro-brasileiras, porque nesse caso temos muitos alunos de outras denominações religiosas que poderiam se sentir discriminados em suas crenças se fizermos isso (PROFESSOR REDE MUNICIPAL DE OLINDA).

Muita coisa pode ser trabalhada na História da África, mas as religiões acho que não, pois temos outras disciplinas, como o Ensino Religioso, que podem dar conta disso (PROFESSORA REDE ESTADUAL DE RECIFE).

A partir das entrevistas feitas com representantes das secretarias, gestores e professores das escolas estaduais e municipais de Recife e Olinda, procuramos compreender como os discursos expressam posições políticas acerca do que deve e não deve ser ministrado em sala de aula e se a história dos negros é entendida apenas como um dito legal, que evidencia uma cultura que fez/faz parte da construção do Brasil, ou se apresenta outros elementos que

n.1 1 p.122-138

jan./abr. 2017 eISSN 2178-8359


extrapolem essa percepção. Buscamos verificar também se há a compreensão/defesa nas escolas pesquisadas de que as temáticas da cultura afro-brasileira sejam/devam ser trabalhadas de forma interdisciplinar.

Neste aspecto, foi evidenciado de modo hegemônico, através da interpretação das falas com uso dos conceitos de hegemonia da TD e de relações de sentido da AD, que o ensino de História da África deve ser desenvolvido de forma interdisciplinar, procurando se articular com outros assuntos correlatos em várias disciplinas, tais como cidadania, direitos humanos, etc., contudo, professores e gestores entrevistados compreendem o negro e o lugar que este ocupa neste processo de interdisciplinaridade como sendo o de um ator social com necessidade de diferenciação de sua cultura, mas não de seu personagem histórico o escravo, ou seja, institui-se a necessidade de melhor posição para o negro, mas sem desvinculá-la da escravidão:

[...] trabalhamos a cultura africana e com isso os alunos percebem que os negros influenciaram muito a nossa cultura. Eles começam a perceber que o negro não é só escravidão, que tem outras coisas também. Agora acho que a escravidão passou, mas os assuntos devem passar por ela porque ela constituiu o negro e sua cultura no Brasil. Sou contra quem defende que não se deve discutir a escravidão na História da África. Faz parte da história, não podemos negar esse passado que pode ter sido desonroso para o negro, mas foi importante para o Brasil como um todo (GESTORA REDE MUNICIPAL DE RECIFE).

Aqui as professoras costumam trabalhar de forma bem enriquecedora para que o aluno possa perceber as diferentes culturas, dentre elas, as afro-brasileiras. O negro foi muito importante como mão de obra escrava, pois sem ele não teríamos construído o que construímos. É igual aos nordestinos em São Paulo que sem eles não se tinha as coisas que lá existem (GESTORA REDE ESTADUAL DE OLINDA).

Vejo que o negro hoje reivindica seu espaço e ele, ele sofreu muito com a escravidão. Se não fosse a escravidão talvez ele ocupasse um lugar melhor na sociedade. Agora ele foi importante porque foi ele quem no período das grandes monoculturas fez esse país crescer com seu trabalho escravo. Infelizmente o lugar que ele ocupou em suas origens aqui foi de inferioridade e ainda o é por causa desse passado e isso dará muito trabalho para nós mudarmos (PROFESSOR REDE MUNICIPAL DE RECIFE).

Nessas falas observe-se que a posição do negro está associada à diversidade cultural com uma localização e contribuição específica de sua cultura, porém esta contribuição vincula-se a memória, ainda fortemente circulante, de sua condição de escravo. Desse modo é que uma concepção de reparação histórica, através de ensino de História da África, enunciativamente e politicamente encontra-se distante desses discursos, pois a forte influencia de uma ideologia da escravidão imprime dificuldades no que se refere a colocar o negro em outros patamares que não o de um construtor submisso do país. 
Entretanto em relação a posições acerca de uma reparação histórica, discursos contrahegemônicos emergiram e ao aparecerem esboçaram preocupação com um trato específico de história e cultura afro, associando-a ao reconhecimento de danos e à ascensão social do negro:

\begin{abstract}
Trabalhamos com todos os elementos possíveis para desvincular o negro dessa imagem de escravidão e submissão que por tanto tempo o colocou à margem da sociedade. Nos planejamentos pedagógicos não deixamos de colocar a temática em discussão junto com os professores e coordenadores para que possamos refletir sobre o que podemos fazer nesse sentido de reparar um mal histórico e não se surpreender ao ver o negro ou a negra ocupando cargos considerados importantes em nossa sociedade (SECRETARIA REDE ESTADUAL).
\end{abstract}

Procuro trabalhar desde a origem do povo africano, desvinculando-o dessa história que está posta de que o negro toda a vida já nasceu escravo e mostro um povo que tem uma riqueza cultural tão linda quanto a nossa. Não trabalho de maneira nenhuma com uma história onde só vou reforçar uma imagem do negro escravo, vagabundo ou sem valor. O meu negro é um negro herói, o meu negro é um negro em que outros negros poderão sentir orgulho e que o que fizeram com esse povo e sua cultura foi fruto da ignorância histórica (PROFESSOR REDE MUNICIPAL DE OLINDA).

Todavia, esses discursos sofreram deslocamentos significativos entre os entrevistados em relação ao lugar do negro quando inserimos ao conteúdo programático do ensino de História da África a temática das religiões afro-brasileiras. Neste caso, de modo hegemônico, entre todos os segmentos entrevistados, especialmente entre os docentes repete-se, se reconhece a importância da alteridade e tolerância à diversidade religiosa, todavia o lugar que as religiões de matriz africana ocupam é o da invisibilidade:

[...] religião é difícil lidar com as não-cristãs, pois é difícil ensinar diversidade com religião, mesmo em História da África, pois cada um tem a sua verdade e não quer abrir mão dela e quando a gente vai trabalhar fora do cristianismo é mais difícil; além disso, a forma estigmatizada como a sociedade trata essas religiões como Candomblé e Umbanda pra mim só fazem piorar o lugar do negro em nossa sociedade. Se é assim, não vejo razão em abordá-las (PROFESSORA REDE ESTADUAL DE RECIFE).

Ainda se faz necessário um trabalho de conscientização com as religiões afro. Reconhecemos que elas, se não simbolizadas positivamente, ajudam a inferiorizar ainda mais os afro-descendentes no Brasil mas, esse trabalho, reconheço que para os professores é complexo porque a gente vive num país cristão que tem dificuldade em aceitar as religiões de matriz africana porque junto com elas vem toda uma gama de preconceitos, com associações e representações demoníacas que são ainda do tempo da escravidão (SECRETARIA REDE MUNICIPAL DE OLINDA).

Os discursos expostos, fortemente vinculados a uma ideologia de reconhecimento do cristianismo como obstáculo ao trato com as religiões afro-brasileiras, sinalizam para

Viçosa, $M G \quad$ v.8

p.122-138

jan./abr. 2017 eISSN 2178-8359 
posições de sujeitos que temem enfrentar o preconceito e o estigma que a população negra sofre. Eles são reveladores do quanto ainda se faz necessário insistir e investir em políticas públicas que valorizem as tradições dessa etnia. Neste aspecto, comungamos da ideia de que muito se fez mas, de que um longo caminho ainda estar por se desconstruir/construir no sentido de valorar e tratar com respeito e alteridade a diferença cultural oriunda de negros e outros povos como os indígenas no sentido de valorizar seus status junto à nação brasileira. No caso específico das religiões afro, sabe-se que elas alicerçaram, tendo sido em muitos estados, responsáveis pela manutenção e sobrevivência da cultura africana no Brasil. Sendo assim, como silenciá-las no trato do ensino de História da África?

\section{CONSIDERAÇÕES FINAIS}

Este artigo expôs dificuldades de consolidação da lei 10.639/03 em escolas municipais e estaduais de Recife e Olinda, esboçando consequentemente dificuldades em se enxergar o negro como um sujeito não submisso, respeitando seus valores e crenças. Assim verificou-se, através das entrevistas realizadas sobre o ensino de História da África em Pernambuco, que os discursos dos entrevistados exibem certa oscilação e tensão em relação ao status do negro. Essa tensão e oscilação é evidenciada especificamente quando constatamos o lugar invisível no qual as religiões afro-brasileiras são colocadas neste ensino. Assim, associadas ao lugar do negro a partir da escravidão e ao medo de se enfrentar o cristianismo ou os cristãos, sua ausência nos conteúdos programáticos do ensino de História da África reitera a existência de conflitos e resistências por parte de profissionais em educação, nas escolas pesquisadas, para inseri-las como elemento importante para a formação cultural e social do indivíduo.

Diante disso, percebemos que não será só a instituição de leis que possibilitará um desenvolvimento razoável ou considerável, no caso específico do ensino em questão, pois mais que elas, faz-se necessário um trabalho de conscientização maior que envolve não somente a escola, como a sociedade como um todo, através das mídias oficiais e alternativas, por exemplo, no sentido de diminuir estigmas associados ao negro e as suas crenças no Brasil.

Sendo assim, a elaboração de políticas públicas e leis são válidas, entretanto que venham acompanhadas de processos de debates em vários espaços públicos e não públicos; a escola reitera-se, é um locus privilegiado nesse aspecto, porque tem a oportunidade de expor as construções culturais intolerantes, explicitando os motivos de processos de inferiorização do negro no Brasil terem ocorrido e ocorrerem, fazendo desse diálogo uma alternativa de desconstrução dessas percepções.

(C) Rev. Educ. Perspec.

Viçosa, $M G$

V.8

n.1 p.122-138

jan./abr. 2017

eISSN 2178-8359 


\section{REFERÊNCIAS}

BASTIDE, Roger. As Religiões Africanas no Brasil. São Paulo: Pioneira, 1989.

BRASIL. Lei no 9.394/1996. Diário Oficial da União. Brasília, 1996.

BRASIL. Lei no 10.639/2003. Diário Oficial da União. Brasília, 10 de janeiro de 2003.

BRASIL. Parecer CNE/CP no 3/2004. Diário Oficial da União. Brasília, 22 de junho de 2004.

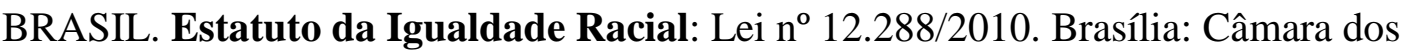
Deputados, Edições Câmara, 2010.

DANTAS, Beatriz G. Vovó Nagô e Papai Branco: usos e abusos da África no Brasil. Rio de Janeiro: Graal, 1988.

FERREIRA, Cristiano C.; OLIVEIRA, Aurenéa M. de. Pluralismo e Religiões Afrobrasileiras: uma discussão no âmbito das escolas estaduais e municipais de Recife e Olinda sobre o lugar do negro no currículo e ensino da História da África. Relatório final de atividades do aluno de iniciação científica (IC) PIBIC/FACEPE/CNPq. Recife: ago. 2013 a jul. 2014.

FERREIRA, Cristiano C.; LOPES, Zilma A.; OLIVEIRA, Aurenéa M. de. Pluralismo, Alteridade e Religiões Afro-brasileiras: uma discussão no âmbito das escolas estaduais e municipais de Recife e Olinda sobre o lugar do negro no currículo e ensino da História da África. Anais do XI Colóquio sobre Questões Curriculares; VIII Colóquio LusoBrasileiro sobre Questões Curriculares; I Colóquio Luso-Afro-Brasileiro sobre Questões Curriculares. Minho: De Facto Editores - Santo Tirso, 2014, v. 1, p. 1191-1196.

GABRIEL, Carmem T.; COSTA, Warley da. Que Negro é esse que se Narra no Currículo de História? Revista Teias, v. 11, n. 22, p. 93-112, maio/agosto de 2010.

GOMES, Nilma Lino (Org.). Práticas pedagógicas de trabalho com relações étnicoraciais na escola na perspectiva da Lei 10.639/03. Brasília: MEC/UNESCO, 2012.

HASENBALG, Carlos Alfredo. O negro nas vésperas do centenário. Rio de Janeiro: Estudos Afroasiáticos, 1987.

INSTRUÇÃO NORMATIVA Nº 01/2012, ESTADO DE PERNAMBUCO. Diário Oficial, 28 de fevereiro de 2012. Disponível em:<http://www.siape.educação.pe.gov.br > Acesso em: 24 mar. 2014.

\begin{tabular}{l|c|c|c|c|c|c|} 
(C) Rev. Educ. Perspec. & Viçosa, $M G$ & v.8 & n.1 & p.122-138 & jan./abr. 2017 & eISSN 2178-8359 \\
\hline
\end{tabular}


LACLAU, Ernesto; MOUFFE, Chantal. Hegemony and socialist strategy: towards a Radical Democratic Politics. London: Verso, 1985.

LACLAU, Ernesto. Discourse. GODDIN, P. (Ed.). The blackwell companion to contemporary political philosophy. Oxford: Blawell, 1993.

MUNANGA, Kabengele (Org.). Estratégias e políticas de combate à discriminação Racial. São Paulo: EDUSP/Estação Ciências, 1996.

MUNANGA, Kabengele; GOMES, Nilma Lino. O negro no Brasil de hoje. São Paulo: Global, 2006.

NASCIMENTO, Abdias do. O genocídio do negro brasileiro: Processo de um Racismo Mascarado. Rio de Janeiro: Paz e Terra, 1978.

OLIVEIRA, Aurenéa M. de. Multiculturalismo, pluralismo e (in) tolerância religiosa: 0 relacionamento dos espíritas pernambucanos com os adeptos de outras religiões (1990-2004). 2006. 353f. Tese (doutorado em Sociologia) - UFPE, Recife.

ORLANDI, Eni. P. Análise de discurso: princípios e procedimentos. 11.ed. São Paulo: Pontes Editores, 2013.

REIS, Maria da C. dos. Educação, identidade e história de vida de pessoas negras doutoras do Brasil. 2012. 182f. Tese (Doutorado em Educação) - UFPE, Recife.

REIS, Maria da C. dos; SOUZA, Edilson F. de; MENEZES, Vilde G. de. Desafios para a política educacional: a presença negra na configuração escolar. Revista Brasileira de Política e Administração da Educação, v. 30, p. 619-634, 2014.

ROSEMBERG, Fúlvia; BAZILLI, Chirley; SILVA, Paulo V. Baptista. Racismo em Livros Didáticos Brasileiros e seu Combate: uma revisão da literatura. Educação e Pesquisa, São Paulo, v. 29, n. 1, p. 125-146, jan./jun. 2003.

SANTOS, Sales Augusto. A Lei no 10.639/2003 como Fruto da Luta Anti-Racista do Movimento Negro. In: SECAD. Educação anti-racista: caminhos abertos pela Lei Federal no 10.639/2003 SECAD/MEC. Brasília, 2005.

SILVA JUNIOR, Hédio. Anti-racismo: coletânea de leis brasileiras federais, estaduais e municipais. São Paulo: Editora Oliveira Mendes, 1998.

SILVA, Vagner G. da. Candomblé e umbanda: caminhos da devoção brasileira. São Paulo: Editora Ática, 1994. 
SILVA, Vagner G. da. Reafricanização e Sincretismo: interpretações acadêmicas e experiências religiosas. In: CAROSO, Carlos; BACELAR, Jeferson (Org.). Faces da tradição afro-brasileira. Rio de Janeiro: Pallas, Salvador, BA, CEAO, 1999.

\footnotetext{
Aurenéa Maria de Oliveira - Professora adjunta III do Centro de Educação da Universidade Federal de Pernambuco (UFPE). Doutora em Sociologia pela UFPE. Pós-doutorada pela Pontifícia Universidade Católica do Paraná. E-mail: aurenea@ yahoo.com.br

ii Maria da Conceição dos Reis - Professora adjunta do Departamento de Administração Escolar e Planejamento Educacional do Centro de Educação da Universidade Federal de Pernambuco (UFPE) e Doutora em Educação pela UFPE. E-mail: cecareis@ hotmail.com

iii Vilde Gomes de Menezes - Professor adjunto da Universidade Federal de Pernambuco e Doutor em Ciência do Desporto pela Universidade do Porto (Portugal). E-mail: vildemenezes@ hotmail.com

${ }^{\text {iv }}$ Cristiano Cavalcante Ferreira - Professor em nível de magistério, onde atuei como professor durante dois anos na função de estagiário. Pedagogo em formação pela Universidade Federal de Pernambuco. E-mail: chryscavalcante@ hotmail.com
}

\section{NOTAS}

\footnotetext{
${ }^{1}$ Por relações de sentido Orlandi entende a memória que circula historicamente e que é expressada nos discursos por meio de enunciações que se filiam a ideologias e que identificam posições políticas dos sujeitos que as reverberam (ORLANDI, 2013).
}

Submetido em: 17-07-2016 - Aceito em: 16-10-2016.

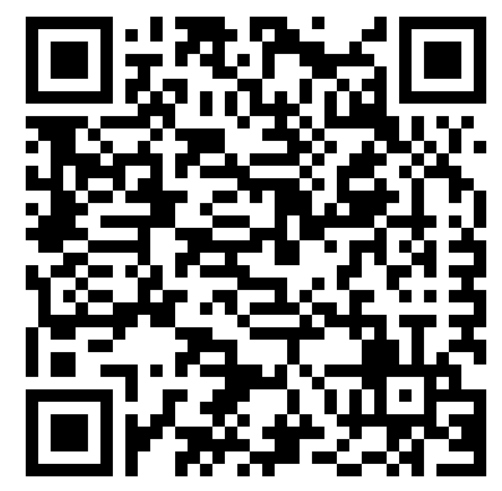

